\title{
Interação social em aulas de educação física
}

CDD. 20.ed. 796.05

\author{
Braulio ROCHA* \\ Pedro José WINTERSTEIN* \\ Silvia Cristina Franco AMARAL* \\ ${ }^{*}$ Faculdade de Educa- \\ ção Física, Universida- \\ de Estadual de Campi- \\ nas.
}

\begin{abstract}
Resumo
0 estudo analisou formas de interação social que ocorrem durante a prática de jogos infantis. A perspectiva histórico-cultural, em especial as contribuições de Vigotski, foi o fundamento teórico para pensarmos a interação social. A pesquisa, caracterizada como observação participante, foi realizada com crianças de nove a 11 anos. A proposta de condução das aulas pautou-se nas aulas abertas, procurando incentivar as crianças a modificarem as regras dos jogos, permitindo que houvesse uma maior chance de interação entre as mesmas. Os dados obtidos no trabalho de campo foram categorizados em três esferas situacionais: participação, atividade e relacionamento. A partir da análise destas esferas é possivel afirmar que é no contato entre indivíduos no ambiente educacional, de forma ativa e comprometida, que a interação social ocorre efetivamente de maneira mais interessante, pois exigem dos alunos atitudes que respondam aos problemas e divergências evidenciados entre eles, muitas vezes, sem a imposição do adulto.
\end{abstract}

UNITERMOS: Educação física; Interação social; Internalização.

\section{Introdução}

É de fim e de recomeço a história de João e Maria $^{1}$ em "agora eu era" o herói, a princesa, o bicho, o rei, a noiva... Nesse faz de conta de um tempo presente e passado, num quintal separado da "noite que não tem mais fim", as crianças brincam suas vidas e aprendem a com-viver. Este texto diz respeito a essas experiências, portanto, é um estudo motivado por questionamentos acerca da importância educativa da prática de jogos e atividades coletivas em que as crianças negociam seus papéis e as leis que os regem, enfim, da interação social constituída e constituinte dos sujeitos.

No decorrer de nossa prática docente é possível identificar entre os alunos, falas e gestos que ditam suas condutas em diferentes situaçôes; é possível perceber a interação entre os mesmos que definirá, independente ou não do adulto, do professor, quem deve participar ou não da brincadeira, quem será o "bedel, o rei e/ou o juiz". Destaca-se assim, a importância do educador e de suas opções pedagógicas para viabilizar um ambiente favorável à educação. Cabe a ele ajudar as crianças a conduzirem suas práticas de forma crítica e autocrítica, não apenas evitando que decisóes tiranas impostas por algum aluno ou pelo próprio professor reinem, mas, principalmente, valorizando o diálogo e a discussão entre os sujeitos do processo.

Inscreve-se na origem da teoria sua relação com o olhar - nas palavras do poeta Gil, "teoria em grego quer dizer o ser em contemplação”. A prática, ligada à reflexão teórica, -ou práxis - caracteriza-se pela ação, pela construção, pelo exercitar das teorias que lhe servem de balizas. Nossas balizas estão "fincadas" na teoria histórico-cultural, em especial nos estudos de Vigotski. O ambiente social em que vivem os sujeitos é considerado o ponto central a estes estudos. Esse ambiente constitui e é constituído pelos sujeitos, pela interação social, lugar onde os símbolos e significados são elaborados. Temos aqui precisamente o que define a inovação, a proposta original de Vigotski para compreender a formação do sujeito, ou seja, em sua teoria, o ser social se individualiza a partir do seu contato ativo cada vez maior com o outro. Nessa concepção, como enfatiza DAVIS (2005, p.43), 
a criança além de ativa é, essencialmente, interativa. $\mathrm{Na}$ verdade, diferente de outras teorias psicológicas, a sócio-histórica vê o psiquismo humano como uma construção social, que resulta da apropriação, por parte do sujeito, dos conhecimentos e das produções culturais da sociedade em que vivem, por intermédio da mediação da própria sociedade. Entendendo-se por "mediação" a necessária intervenção de algo entre duas coisas para que um tipo específico de relação se estabeleça.

Para um melhor entendimento do que se aponta como meio ou ambiente social, esclarecese que meio é tudo que rodeia o individuo, outros sujeitos e objetos. No entanto, é com os outros sujeitos que essa formulação recíproca de significação será completa, pois somente entre sujeitos é que os signos têm seus significados estabelecidos. E nesse contexto de conflito entre dois indivíduos e suas perspectivas de mundo que,

\section{Metodologia}

As aulas de educação física foram ministradas no Programa de Desenvolvimento e Integração de Crianças e Adolescentes (Prodecad), que atende crianças em três subprogramas: Pré-Escola, Apoio a Escolaridade I ( $1^{\mathrm{a}}$ a $4^{\mathrm{a}}$ séries) e Apoio a Escolaridade II ( $5^{\mathrm{a}}$ a $8^{\mathrm{a}}$ séries).

Para se matricular nessa escola de ensino nãoformal, no subprograma de Apoio a Escolaridade I $\left(1^{\mathrm{a}} \mathrm{a} 4^{\mathrm{a}}\right.$ series) ou nos outros programas oferecidos pela instituição de ensino, a criança deve atender aos seguintes critérios de admissão:

- Ser filho ou dependente legal das funcionárias e funcionários da Unicamp e Funcamp;

- Ter matrícula no Sérgio Porto de $\mathrm{l}^{\mathrm{a}}$ a $4^{\mathrm{a}}$ série.

O Prodecad, “[...] tem como objetivo oferecer as mais diversas possibilidades de expressão de modo a propiciar a produção de conhecimento e cultura por meio dos jogos e brincadeiras e das artes" (RIBEIRO et al., 2001, p.17). Para que isso ocorra, a instituição oferece um amplo espaço para brincar, ateliês de artes plásticas, oficinas de musica e movimento e profissionais em constante processo de formação em arte-educação.

Para alcançar seus objetivos educacionais, o Prodecad dispõe de Oficinas Culturais que possibilitam a expressão dos educandos, utilizando, de modo criativo, diferentes formas de linguagem. Atualmente, como entende Lemos (2006), é estabelecida a interação social.

Radicalmente diferente da interação entre sujeitos, na relação dos indivíduos com os objetos somente um dos elementos e capaz de significar o outro, o que estabelece, para este caso, uma forma unilateral de significação. Em ambos os casos há a busca de significação do mundo para o indivíduo, todavia, enquanto uma é negociada entre sujeitos, a outra é unilateralmente concebida.

É no primeiro caso que este trabalho se detém, existindo um aspecto fundamental a influenciar o processo: a subjetividade. Assume-se o indivíduo como historicamente constituído e considera-se que ele atua ativamente em seu meio, internalizando e elaborando cultura.

Com esses pressupostos em mente, o presente estudo foi desenvolvido, buscando estudar as diferentes formas de interação social existente entre os alunos e entre estes e o professor.

são quatro as oficinas do programa: Artes, Educação Motora, Oficina da Palavra e Oficina Interdisciplinar - sendo esta o ponto em que se encontram, com maior ênfase, diferentes formas de linguagem. Todas oferecem possibilidades de utilização de diferentes linguagens "[...] modo como se comunica algo para alguém, ou seja, a maneira como o ser humano expressa as relaçóes que ele tem com o mundo [...]" (RIBEIRO et al., 2001, p.14) -, para a construção do conhecimento compartilhado.

Na oficina de Educação Motora, o conteúdo é dividido em três grandes áreas: modalidades esportivas, jogos cooperativos e jogos e brincadeiras tradicionais. É importante notar que, mesmo as atividades voltadas para as práticas de modalidades esportivas, assumem uma forma adaptada às capacidades e possibilidades dos alunos. Deste modo, jogos e brincadeiras constituem as principais ferramentas de ensino e construção de conhecimento nas oficinas de Educação Motora, nas quais “o jogo possui centenas de variaçôes, gerando novas dificuldades levando os alunos a tomar consciência da atividade realizada, estimulando a criatividade e a descoberta" (Puletini et al., 2006).

A escolha do local de pesquisa, Prodecad, se deu por entendermos que aquela instituição se aproxima, em alguns aspectos, dos procedimentos 
didático-pedagógicos e com o conteúdo que seriam conduzidos neste estudo.

O grupo investigado foi o de crianças de $3^{\mathrm{a}}$ e $4^{\mathrm{a}}$ séries, todas voluntariamente inscritas para participar da pesquisa. O fato dos alunos poderem participar ou não da atividade proposta pelo pesquisador, entrando e saindo quando bem entendiam, gerava uma variação no número de participantes do projeto. Crianças de outras séries e não participantes da pesquisa puderam frequentar o ambiente em que as atividades foram desenvolvidas; no entanto, suas açōes e falas foram desconsideradas durante a transcrição das fitas. Esse procedimento foi adotado para possibilitar a rigidez metodológica necessária à pesquisa sem, no entanto, interferir na dinâmica da instituição de ensino - que tem por principio a não seriação e a possibilidade da participação de todos que quisessem vivenciar as atividades propostas.

A escolha da faixa etária das crianças aconteceu por acreditarmos no que nos diz VIGOTSKI (2000), que a medida que há o desenvolvimento da criança os jogos evoluem de situação imaginária com regras ocultas para situação de regras claras e imaginação oculta.

A interação social aqui estudada o foi, por meio de 10 jogos escolhidos, em aulas de educação física. Metodologicamente conduzimos as aulas, fundamentados na concepção aberta, que privilegia o debate e a co-decisão em aspectos inerentes ao processo de ensino.

O termo concepções abertas de ensino foi amplamente divulgado no Brasil pelo trabalho de Hildebrandt e Laging (1986), em "Concepções abertas de ensino da educação física"; livro que reflete sobre as possibilidades de ensino nas aulas abertas e dá alguns exemplos práticos de aulas em que os alunos são convidados a participar da construção do conteúdo a ser ministrado, do gerenciamento do tempo e da organização das atividades. "O planejamento e a execução do ensino são, desse modo, tarefa de todos os que dele participam, ou seja, do professor e dos alunos" (HiLDEBRANDT \& LAGING, 1986, p.11).

Essa concepção fundamenta-se no conceito de interacionismo e os significados para as suas açōes são construídos pelos indivíduos durante um processo de interação social com seus pares (TAFFAREL, 1993).

As hipóteses que sustentam o processo interativo justificam a importância dada por HILDEBRANDT e LAGING (1986) a possibilidade dos alunos refletirem e planejarem juntamente com o professor as situações de ensino durante a aula. Os autores defendem que a aprendizagem tem que ser significativa para os indivíduos e ocorrer em conjunto com outros indivíduos; além disso, observam também que são os conflitos e as tentativas de resolvê-los que vão possibilitar a construção do conhecimento.

É considerando essa possibilidade de ensino que HiLdEBRANDT e LAGING (1986, p.17) criticam o "monopólio do planejamento do professor" e convidam os alunos a lutar contra o cumprimento acrítico das regras preestabelecidas.

Cada decisão do professor pode ser apresentada de tal forma que deixe espaço aberto ou limitado ao aluno, restando a este, em último caso, apenas aproximar-se da decisão ou refutála, o que por sua vez devera resultar em conseqüência para o professor. Numa concep̧̧ão aberta de ensino, solicita-se ao aluno que participe nas decisōes (HildebrandT \& LaGing, 1986, p.11, grifo dos autores).

Os autores defendem diferentes níveis de abertura durante as aulas, do aberto ao limitado, mas, um limite que permite, no mínimo, a possibilidade de o aluno refutar as decisóes e escolhas do professor. Dessa forma, a concepção aberta de ensino prioriza a formação de um cidadão critico e autônomo, capaz de analisar a situação e tomar decisões conforme suas necessidades e desejos.

O professor arranja situações onde os alunos podem fazer as primeiras experiências de movimento. Oferece a eles possibilidades de definir suas situaçōes autonomamente. Durante o processo de exploração abrem-se sempre, novamente, situações de interação e conversação, onde os alunos podem refletir suas experiências (Universidade Federal de Pernambuco/ Universidade Federal de Santa Maria, 1991, p.22).

Nesse contexto, é possível definir o conhecimento construído durante a aula como algo entre "o que o professor ofereceu" e "o que os alunos foram capazes de problematizar e realizar". Esse algo, justamente nessa posição intermediária, permite conceber o processo de ensino e aprendizado não apenas na direção professor/aluno, mas também entre os alunos e na direção que vai deles para o professor.

Neste estudo optamos pelas aulas abertas com grau médio de possibilidades de co-decisão (HildebRANDT \& LAGING, 1986) que permite prever um poder igual para cada parte, aluno e professor, nas decisōes sobre objetivos, conteúdos, maneiras de transmissão e resultados de aprendizagem.

Abre-se um parêntese para explicar mais a fundo esses quatro conceitos aplicados durante as aulas 
ministradas. A escolha dos objetivos dos encontros ocorreu durante o processo decisório entre a forma como os alunos idealizavam as modificaçôes do jogo proposto por eles e a prática desses jogos. Assim, o objetivo transversal das aulas foi o de praticar os jogos propostos e neles efetuar modificações.

Os conteúdos - diferentes jogos - foram escolhidos entre a gama de jogos que os alunos já praticavam no Programa de Desenvolvimento e Integração de Crianças e Adolescentes (Prodecad). Tanto o pesquisador/professor quanto os alunos foram responsáveis pela seleção dos jogos praticados durante a pesquisa.

Quanto à maneira de transmissão, houve uma predominância maior de decisões tomadas em conjunto, procurando atender a concepção aberta das aulas. Contudo, o professor planejou suas aulas previamente, procurando debate-las oportunamente com os alunos, na medida que as mesmas ocorriam.

Já em resultado da aprendizagem, permitiu-se que os alunos individualmente avaliassem os resultados de suas decisões durante o processo de tomada de decisões em aula. Desta forma, o pesquisador/professor atuou na direção de evidenciar as problemáticas que surgiram durante as atividades.

Observou-se, durante os encontros, que foram propostos, jogos praticados pelos alunos em momentos livres ou em suas aulas. Eles também puderam sugerir outros jogos, que gostariam de jogar. $\mathrm{Na}$ condução da aula, incentivou-se que sugerissem alterações na forma de jogá-los. As alteraçôes ocorreram na dinâmica $\mathrm{da}$ aula, na qual os alunos paravam, refletiam, procuravam soluções, retomando logo a seguir o jogo em si.

\section{Revisão bibliográfíca}

\section{As contribuições de Vigotski para pensarmos a interação social}

$\mathrm{Na}$ teoria histórico-cultural, o ambiente social em que vivem os sujeitos é considerado por Vigotski o centro de sua teoria. É nesse ambiente, que constitui e é constituído pelos indivíduos, que ocorrem as interaçōes sociais entre os sujeitos. Em sua teoria, o ser social se individualiza a partir do seu contato ativo cada vez maior com o outro.

Como já explicitamos na introdução, é com os outros sujeitos que essa formulação recíproca de significação mediação entre pessoas - é completada, pois somente entre sujeitos éque os signos têm seus significados estabelecidos.
Para tornar ainda mais eminente a necessidade de alteração da forma de se jogar, promoveu-se a mudança de material utilizado no jogo (ex: bola grande de plástico na atividade de handebol) e do campo a ser utilizado (ex: pega-pega com restrição do campo do jogo à quadra), entre outras. Durante as aulas, as mudanças na prática dos jogos sugeridas pelos alunos foram, em parte, inovadoras (ex: a forma como a corda foi utilizada durante o jogo pega corrente, para manter todos do grupo unidos) e, em parte, alteraçóes que eles já estavam habituados a realizar para viabilizar os seus jogos diários (ex: prender a corda no hidrante para que os outros pudessem saltar, de forma que fosse necessário somente um aluno para bater a corda).

A possibilidade de alteraçóes dos jogos e $\mathrm{o}$ incentivo dessa forma de jogar -mesmo no caso de alteraçóes já realizadas pelos alunos - teve por objetivo ressignificar suas práticas por meio do embate entre as suas propostas. Esse embate trouxe a tona conflitos entre as formas como os alunos idealizavam as possíveis soluções para os problemas encontrados durante a recriação de seus jogos. Como na situação em que o sujeito tinha que buscar, no dialogo com o outro, as saídas para os problemas comuns. Para tanto, foi privilegiado um ambiente educacional de respeito e compreensão, o qual contou com a presença de diferentes formas de interaçôes sociais entre os indivíduos.

A coleta de dados ocorreu durante 10 encontros semanais, sendo as aulas filmadas e transcritas pelos pesquisadores, totalizando 233 minutos de gravação.

O projeto foi submetido e aprovado pelo Conselho Nacional de Ética em Pesquisa.

Assume-se o indivíduo como historicamente constituído e considera-se que ele atua ativamente em seu meio, internalizando e elaborando cultura. Pode-se afirmar que as significações em cada indivíduo jamais serão plenamente coincidentes (VIGOTSKI, 1999), visto que cada indivíduo conta com uma personalidade - "conjunto das relações sociais" (VIGOTSKI, 2000, p.35) - distinta.

Assim, em cada verbalização ou ação do sujeito, existe a possibilidade de significação por outrem, que vai codificar o outro através de sua fala e gesto - que são a palavra e a ação significadas (SMOLKA, 2000a). Para tanto, a subjetividade individual será requisitada, o que afirma a singularidade de 
interpretação e significação para cada sujeito, com base em sua experiência de vida. No entanto, como já foi exposto, nesse processo existem coincidências entre as formas de interpretar os signos pelos sujeitos, e são essas coincidências que viabilizam a possibilidade de interação entre eles.

Ao pensar sobre a linguagem VIGOTSKI (2003) diz que, a palavra é uma das ferramentas mais importantes na constituição do pensamento humano, mas não descarta a possibilidade da ação humana ter sua função de linguagem através de diferentes sistemas semióticos como os gestos, por exemplo. Isto fica claro quando o autor descreve a ação da criança que tenta pegar o objeto, falhando em sua tentativa. A ação então é significada pela mãe, que percebe o movimento como o gesto de apontar. Com o passar do tempo, segundo o autor:

[...] ocorre uma mudança naquela função do movimento: de um movimento orientado pelo objeto, torna-se um movimento dirigido para uma outra pessoa, um meio de estabelecer relação. $\mathrm{O}$ movimento de pegar transforma-se no ato de apontar. [...] De fato, ele só se torna um gesto verdadeiro após manifestar objetivamente para os outros todas as funçôes do apontar, e ser entendido também pelos outros como tal (Vigotski, 2003, p.74-5).

Revela-se então que a linguagem é ação (vocalização, silêncio, movimento, estatismo, postura corporal, feição, dentre outros) dirigida ao outro, e que é passível de ser significada por este. Para que o uso da linguagem seja efetivo, a ação deve ser intencionalizada - carregada de intenção do agente - e inteligível para quem quer que a ação tenha sido dirigida. Para este último fator ocorrer da forma mais precisa possível, é importante que os indivíduos envolvidos no processo de comunicação compartilhem alguns signos e suas respectivas significaçôes; caso contrário, a comunicação terá seu papel comprometido por diferenças intersubjetivas na significação.

Nesse processo de significação é necessária a presença de no mínimo dois indivíduos que, em interação social, vão estabelecer acordos mútuos para a criação e uso dos signos e de suas respectivas interpretações, as quais podem ser mais ou menos duradouras, conforme a situação em que foram elaboradas.

A interação social assume então um papel fundamental, uma vez que é por meio dela que os indivíduos compartilham suas experiências e juntos formulam algo que antes não estava presente em nenhum dos dois indivíduos (Pino, 2000).
A interação social e as experiências que elas proporcionam em meio social vão constituir as funçôes psicológicas superiores do individuo - termo cunhado por Vigotski e citado por PEDROSA (1996, p.27, grifo do autor), que pode ser explicado sinteticamente como "[...] a projeção no plano pessoal (esfera privada) da trama das relaçôes sociais (esfera pública) [...]”. Essa informação é que proporciona a compreensão da complexidade desse processo, uma vez que o indivíduo é constituído pelo ambiente social e responde a ele segundo suas experiências sociais únicas, que são ativamente introjetadas por ele.

$\mathrm{Na}$ concepção de Vigostski, as experiências vivenciadas entre pessoas agregam-se ao sujeito e o constituem, assim como as experiências já introjetadas são socializadas, constituindo o ambiente social e regulando as formas de os indivíduos interagirem. A interação social revela-se então um processo de mútua constituição do sujeito e do ambiente social, um vaie-vem que modifica o meio e promove, concomitantemente, o desenvolvimento do indivíduo. Nessa teoria, o desenvolvimento humano é impulsionado pela aprendizagem que se dá no ambiente social e de interação entre sujeitos.

Para que haja o desenvolvimento faz-se necessária a mediação de um outro ser social mais experiente. É nessa relação que a aprendizagem vai se dar por meio da troca de experiência entre indivíduos. Nesse caso, ocorre a internalização de aspectos que são apresentados ao indivíduo e mediados pelo outro.

VIGOTSKI (2003) afirma que o responsável por criar uma zona de desenvolvimento proximal na criança é o brinquedo, que pode ser definido como "[...] um mundo ilusório eimaginário onde os desejos não realizáveis podem ser realizados [...]" (VIGOTSKI, 2003, p.122).

Este mundo ilusório é o local onde a criança se comporta como se ela fosse mais velha do que é na realidade, por esse motivo pode ser encarado como fator de grande influência para o desenvolvimento, pois leva a criança a agir independentemente daquilo que vê, atuando em um plano mais cognitivo do que concreto, desligando-se de vínculos que possuía em estágio anterior de desenvolvimento. Ao se relacionar com o brinquedo a criança estará jogando.

$O$ brinquedo cria na criança uma nova forma de desejos. Ensina-a a desejar, relacionando seus desejos a um "eu" fictício, ao seu papel no jogo e suas regras. Desta maneira, as maiores aquisições de uma criança são conseguidas no brinquedo, aquisiçōes que no futuro tornar-seão seu nível básico de ação real e moralidade. (VIGOTSKI, 2003, p.131). 
Segundo VigOTSKI (2003), a evolução do brinquedo pode ser verificada de acordo com a evolução do jogo nas crianças, na transição de situação imaginária às claras e regras ocultas, para jogos com regras às claras e uma situação imaginária oculta. Estas regras tornamse cada vez mais rígidas conforme a evolução do jogo, tornando este mais tenso e, concomitantemente, exigindo maior atenção da criança.

A internalização é um conceito importante e contribui para o presente estudo. É por meio desse processo que o que está externo ao sujeito orgânico é reformulado para integrar o indivíduo social. Assim, o que antes foi relação entre pessoas passa a ser um modo de relação do sujeito para consigo,

\section{Resultados e discussão}

\section{Jogo e interação social: construtos sociais que constituem o sujeito}

É nas fábulas musicais de um grupo de saltimbancos que Chico Buarque mostra como se encenam novas formas de organização social. Com "esperteza, paciência, lealdade, teimosia", todos sonham com uma cidade ideal, brincam de escondeesconde, reclamam das regras e ordens e, por fim, Todos juntos, tentam mudá-las: "e mais dia menos dia a lei da selva vai mudar. Todos juntos somos fortes, somos flecha e somos arco, todos nós no mesmo barco, não há nada pra temer". É dessas experiências compartilhadas que trata esta parte do texto. Nela são apresentadas as categorias de interação social encontradas durante as aulas ministradas nesta pesquisa.

Essas categorias foram formuladas por sua similaridade em situações de interação. É importante ressaltar que para tanto foi observado o conjunto de ações (falas, posturas, movimentos, gestos, entre outros), considerando-se a percepção individual como pesquisador - das intençôes dos alunos em suas açôes. Por isso, foi significativa e fundamental a efetiva inserção do pesquisador no grupo de alunos e no ambiente de ensino.

As categorias de interação são aqui formuladas para dar conta de exemplificar os diferentes indícios de aprendizado e desenvolvimento resultantes da ação (pensada e formulada a partir das motivaçōes, desejos e objetivos do sujeito), da reação (do meio social apoiando ou rechaçando as ações do indivíduo) e da interpretação das reações; esses indícios permitirão ao como salientam SMOLKA e LAPLANE (2005). Então, o sujeito é afetado a cada instante por suas relações com o meio e se constitui através desses contatos. $\mathrm{Na}$ outra direção, o indivíduo também exerce força modificadora em seu ambiente ao proceder e ao exteriorizar ações baseadas em suas internalizações. É pela forma como o sujeito responde ao ambiente que se revela aos outros indivíduos as prováveis internalizações - impressões pessoais sobre a realidade - daquele ser social (SANTIGOSA, 2003).

Foram apresentados os principais posicionamentos e escolhas do presente estudo quanto ao sujeito, ao ambiente social e às suas formas de constituição por meio da internalização intermediada pelo outro.

indivíduo reformular suas atitudes em uma situação semelhante no futuro e ao(s) professor (es) pensar estratégias, conteúdos que lancem problemas capazes de desenvolverem seus alunos.

Esse processo - que ocorre entre ação, reação e interpretação da sua própria ação em relação às respostas do meio - encadeado e mútuo entre indivíduos é que vai constituir a interação social que vão ajudá-los a internalizar o que o meio lhes oferece e que, por outro lado, vão posicioná-los como agentes de mudança desse mesmo meio.

Durante a análise da interação social percebeuse que elas poderiam ser rearranjadas em três esferas situacionais que dizem respeito à participação dos sujeitos no jogo, à prática ou decisóes sobre a atividade e ao relacionamento entre os mesmos.

Durante a realização dos jogos, a medida que há uma zona de desenvolvimento proximal colocada a cada sujeito envolvido no processo e outros apresentam para este mesmo problema uma zona de desenvolvimento real, várias situaçōes de interação surgiram.

\section{Esfera situacional participação}

$\mathrm{Na}$ esfera que denominamos de participação são agrupadas as categorias que envolvem interação social regulatórias das açôes dos alunos nas atividades, tais como exclusão, incentivo e inclusão.

Descrevemos alguns trechos a seguir que nos permitem vislumbrar estas formas que a interação social pode assumir.

A exclusão no ambiente de jogo pode ocorrer por diversos motivos dentre os quais, habilidade não 
madura ainda para aquele tipo de jogo, desafetos entre alunos, questôes de gênero, entre outras razões. A exclusão pode levar o sujeito a ser impedido de participar do jogo ou de determinado time.

$\mathrm{Na}$ transcrição de situação de aula a seguir, é possível observar como "S" tenta fazer com que "I" mude de time para que ela possa ficar em seu lugar. Com a recusa de "I", a aluna "S" acaba por integrar o time formado por alunas, deixando assim o aluno "D" sozinho, segurando a outra ponta da corda. Isso torna possível inferir que nenhuma das duas alunas queria deixar suas amigas para compor um time com um aluno.

"S": - Vai "I" com ele.

Ao pedir para que a "I" fosse ajudar o "D", pois ela queria ficar no time de "A" e "H".

"I": - Não. Recusando-se.

"S": se une ao time das alunas e ajuda a puxar o " $\mathrm{D}$ " por intermédio da corda.

"D": - Não vale tio. Diz revelando que era injusta a condição dele contra as quatro alunas.

Nesse outro trecho, há incentivo, seguido de orientação, uma vez que o aluno "J" parecia não saber ao certo o que deveria ser feito ao ser pego.

"D": - Vai pega um, "A". Ao indicar a aluna

"A" que ela já poderia pegar, pois o jogo havia começado.

"A"": - Peguei. Ao tocar o braço do aluno "J".

"D": - Você ajuda ela "J". Aluno "D" orienta

"J" ao apontar para a "A", que deveria ajudar.

Nesta outra descrição também podemos notar incentivo já que " $S$ " mostra-se muito envolvida no jogo e promove incentivos, no intuito de que outros alunos também se envolvam no jogo e nas açōes que devem ser tomadas nele.

"L": inicia sua corrida para o outro lado.

Pesquisador: adverte - Não pode voltar "L".

"S": - Voltou. Acusando-o de ter voltado para

o campo atrás da linha verde. Mas ela segue na tentativa de pegá-lo.

"L": consegue driblá-la.

"S": - Pega professor. Vamos levantar o "L".

Estimulando o pesquisador a capturar o aluno

"L" e, em seguida, estimulando os alunos a ajudar a levantá-lo.

Esse tipo de interação parece reforçar ações consideradas positivas e desejáveis pelos sujeitos do grupo, reforçando-as e aumentando a sua intensidade e frequência. A cobrança lembra os indivíduos do que é esperado deles e chama a sua atenção para o que deve ser realizado e de que forma. $\mathrm{O}$ incentivo ressalta o que está sendo realizado conforme o esperado e motiva as ações nessa direção. Este tipo de interação pode ser considerado um exemplo de inclusão.

\section{Esfera situacional atividade}

Esta esfera remete-nos a prática ou as decisões sobre a atividade, tomada pelos sujeitos. É o acordo sobre as regras, o início, o fim, o campo a ser usado no e para o jogo. Podemos dizer que a situação aparece como cobrança, desafio, orientação, proposição e reconsideração.

A cobrança parece ser importante para que os alunos percebam as exigências do grupo para o cumprimento das regras, alem de melhoria de suas açóes referentes à prática do jogo. $\mathrm{O}$ trecho abaixo retrata bem este tipo de situação.

"I": - Vai gente, e é um, e dois e é três. Impaciente pela demora de "S" e "V" em se arrumar ela tenta iniciar o jogo.

"S": - Espera ai, espera ai, espera ai. Solicitando um tempo maior para que ela se posicionasse na corda e segurasse o saco.

"I": - Gente! Sacudindo a mão direita, tentando apressar as duas meninas para o início do jogo.

O exposto acima nos relembra a importância do meio social para a modificação das ações dos sujeitos do grupo. A cobrança de uma ação específica por um dos membros do grupo revela aquele que é cobrado o que o grupo espera dele. Neste sentido VIGOTSKI (2000, 2003) lembra que todas as funções humanas são vivenciadas primeiramente fora dos sujeitos - em ambiente social - para serem depois experienciadas dentro deles. Assim, o sujeito que e pouco exigido de seu meio provavelmente desenvolvera menos diversidade de resposta a si mesmo.

Outro aspecto importante a ser notado na esfera atividade é que nesta pesquisa, a orientação ocorreu principalmente entre alunos; o que revela coerência com a opção teórica e pedagógica das aulas, que foram ministradas segundo as concepçōes abertas de ensino.

As aulas abertas privilegiam a tomada de decisōes e ações por parte dos alunos em oposição aos métodos mais tradicionais de ensino, que consideram o professor o detentor do conhecimento e o aluno o receptáculo pronto a receber o conhecimento que o professor oferece.

Nestes trechos abaixo é possível perceber mais uma vez a lógica das aulas abertas, bem como desafio, reconsideração, proposição, formas de interação que compõe para nós esta esfera situacional.

"T": que agora está na posição de quem queima, vai tentar queimar a aluna "V" e passa da linha do seu campo ao tentá-lo. 
"V": reclama. - Não! Então corrige o posicionamento de "T". - Vai, você e lá atrás. Ao mostrando para "T" o local de onde ele deveria fazer os arremessos.

“T”: então recua, aceitando o reposicionamento indicado por "V".

Pesquisador/professor: inicia a explicando das regras do jogo.

"S": - Já sei, já sei. Indicando já conhecer o jogo. Alunas “T” e "B”": não se manifestam.

Pesquisador/professor: Continua a explicando das regras do jogo; agora direcionando a atenção para as alunas que não se manifestaram. "S": toma a palavra e passa a explicar o jogo para as duas alunas, gesticulando e encenando como deveriam ser as açôes das alunas em cada situação do jogo.

"D": - Vai, cada vez mais vai enchendo o último que ficar ganha. Fala alto e olhando para o pesquisador, dando a entender que buscava nele a autorização para fazer esta modificação na regra. Pesquisador/professor: permanece em silêncio e sem sinalizar negativa ou positivamente. Alunos: aceitam a proposta de "D", passam a jogar o jogo com essa nova regra. Quando todos os alunos tinham sido postos para dentro da corda, com exceção de "V" e "S", o pesquisador problematiza a situação suscitada pela nova regra.

A possibilidade de orientação entre alunos vem reafirmar a importância dos alunos se sentirem motivados a participar ativamente e criticamente das aulas, assim como é sugerido por HILDEBRANDT e LAGING (1986), quando defendem as concepções abertas de ensino. Assim, alem de recebido, o conhecimento e re-elaborado pelos alunos e entre eles, o que torna o aprendizado um processo mais significativo e duradouro. Cabe salientar que não é somente a concepção aberta que preconiza este tipo de atitude, há outras propostas como a da obra Metodologia do Ensino de Educação Física e da obra Transformação Didático-Pedagógica do Esporte, só para citar duas.

\section{Esfera situacional relacionamento}

$\mathrm{Na}$ terceira esfera, que diz respeito ao relacionamento, a interação social assume formas como liderança, controle, aceitação e dominação.

A liderança, dominação e aceitação desta liderança mostraram-se formas de interação que via de regra, numa situação de grupo estão altamente relacionadas.
Não é demais lembrar que aqui dividimos formas de interação para didaticamente as identificarmos, mas numa situação cotidiana elas são altamente imbricadas e deflagradoras de maturação grupal e individual.

Estas formas são bastante comuns durante as aulas, indicando que, para os alunos estudados, pode ser difícil trabalhar em grupo, uma vez que para realizar uma atividade coletiva os indivíduos devem dialogar e aceitar os desejos do outro, buscando assim um espaço de compreensão e respeito recíproco. Isto é construído na medida que os sujeitos vão experenciando diferentes situações onde podem se colocar, debater, confrontar-se civilizadamente e tomar decisões cada vez mais conjuntas.

Vale lembrar que, apesar da tensão provocada, tais situações são importantes, pois por meio delas que os sujeitos buscam se afirmar no grupo e mostrar diferenças de pontos de vista e de valores. Isto pode ser notado abaixo:

"D": apos ser convidado insistentemente pelos alunos para participar ele parece está preparado para entrar no jogo novamente. - Deixa eu tirar com alguém ali . Deixa eu tirar com a " $S$ ". Isto passa por cima de situações anteriormente observadas, quando a aluna "I" finalmente escolhe os times com "S".

"I": então diz- Não! E empurra a "S" para trás. "D": aproxima-se de "S" para tirar par ou impar, quando a "I" novamente empurra "S" para trás, para longe de "D".

Aqui se podem identificar duas ações de liderança: a primeira, do aluno " $D$ ", que quer impor a sua vontade de tirar o time com a aluna "S"; a segunda, a da aluna "I", querendo manter a validade da divisão dos times que já haviam sido escolhidos.

É importante notar que o aluno " $D$ " parece perceber como a sua presença no jogo e desejada pelos alunos - pois insistem para que ele participe; nesse contexto, "D" e posto em uma situação na qual se percebe capaz de fazer exigências ao grupo, passando a clara mensagem de que a sua participação no jogo esta condicionada a concessão do grupo aos seus desejos.

No caso contrário, quando o aluno não conta com o apoio dos outros, para a realização de suas vontades, sua interação de imposição é mais truculenta. Assim sendo, os alunos tendem a impor-se de outras formas; pela força, ou impedindo que a atividade continue, o que coloca esse aluno em situação favorável de negociação, caso os demais desejem continuar realizando a atividade.

Nos trechos a seguir é possível perceber que uma vez percebidas as infrações, os alunos impõem punições uns aos outros. 
"H": para bem junto ao pesquisador, que vai bater a corda.

"V": puxa "H" para trás e diz - Eu cheguei primeiro. Ao tentar defender sua posição de primeira da fila.

"H": tenta reagir e voltar a tentar ficar na frente. "S": segura "H" pelos ombros e a impede de tentar avançar para o primeiro lugar na fila (mais próxima da ponta da corda e que e batida pelo pesquisador). "H": então se solta das mãos de "S" e vai para o último lugar da fila, perto da ponta da corda amarrada no hidrante.

Pesquisador, "V", "S" e "I": dando-se por convencidos de que "H" tinha aceitado a posição do grupo em não.

"H": quando a corda começa a ser batida, ela então decide atrapalhar o jogo, e corre para perto do hidrante, impedindo a corda de ser batida. Ela então toma a outra ponta da corda na mão e sai correndo.

"A": entra correndo no campo do outro time com a bola na mão, ameaçando arremessar a bola nos alunos do outro time.

"C": -Não pode.

"D”: - Que é isto? Ambos reclamando da ação da aluna "A" que infringe a regra ao entrar no campo para queimar os alunos do outro time. "A": - Pode sim. A aluna "A" mostra querer infringir a regra e parece não se importar com as reclamações dos alunos.

"D": - E esta linha aqui. Apontando a linha que divide o cemitério de sua quadra. E, em seguida, solicitando a posse da bola. - Pode me dar.

"A": joga a bola no chão e se afasta.

Uma outra forma utilizada pelos alunos para expressar seus julgamentos foi adjetivar o sujeito ou suas ações. Isto pode ser notado nos trechos a seguir:

Pesquisador/professor: aproxima-se de "D”. - Não é questão de ser mais força "D”. Solicita o lenço de volta, assim desclassificando a ação na qual ele utilizou ação agressiva para ganhar a posse do lenço.

"D": - Eu peguei dela, ela nem deixou eu arrumar e já vem pegar. Justifica-se e esconde os lenços nas costas para que o pesquisador não os tome. Pesquisador/professor: estende a mão para "D", exigindo os lenços.

"D": reluta, dando alguns passos e se afastando do pesquisador/professor. Por fim, ele dá os lenços para ele e complementa: - Ela e folgada. Referindose a "V" que a seu ver tinha sido desonesta ao não dar tempo para ele arrumar o lenço.
"V": fica bem junto da linha que determina o campo dela.

"S": então reclama - Passou. O do "T" e até aqui. Em seguida apontando que a aluna "V" está dentro do campo do aluno "T".

"V": então retruca - Não, o campo do "T" e aqui. E mostra no chão a linha atrás dela, indicando que seu posicionamento está correto. "S": então joga a bola na direção da aluna "V", mostrando que aceitou a localização dela como válida.

Nessa passagem acima chama atenção o fato de em alguns momentos os alunos tentarem envolver o pesquisador/professor nas suas discussóes, dando a entender que, se eles convencessem o professor, a discussão estaria terminada. Essa tentativa reforça a ideia de que os alunos vêem na figura do professor o controlador e regulador da atividade. Em caso de conflito -na visão dos alunos - ele deve intervir e todos concordarão, respeitando a sua autoridade.

É importante pensar nessa observação, principalmente quando se lembra que as atividades foram conduzidas de forma a dar espaço para que os alunos dialogassem e exercitassem seu poder de critica e autocrítica. No entanto, quando usam esse artifício de deslocar a discussão entre eles, de forma a integrar o professor no intuito de convencê-lo, mostram que ainda não desenvolveram completamente sua capacidade de argumentar e lidar com a situação de conflito.

As agressóes durante a pesquisa ocorreram sempre que havia uma disputa entre os alunos. Quando dois indivíduos tinham interesses distintos e conflitantes e, ao mesmo tempo, não conseguiam argumentar e defender seu ponto de vista, optaram pela agressão como forma de garantir a realização de seus interesses. Pesquisador/professor: - Vocês preferem assim ou assim a quadra? Ao questionar os alunos acerca de sua escolha, aponta primeiramente para um sentido e depois para o outro, sendo o último a forma que utilizaria duas quadras. "D": - Assim! E aponta para a utilização de uma só quadra. Ao reconsiderar sua intenção. "S": também reconsidera e aponta para a utilização de uma só quadra, balançando o braço e falando: - Assim!

Os alunos inicialmente apontam para a utilização das duas quadras para a realização do jogo. Apos serem questionados novamente, mudam de opinião, aparentemente por perceberem que utilizando as duas quadras eles obstruiriam a passagem dos pais que chegavam para buscar os alunos dentro do prédio do Prodecad, alem de existirem pessoas no local que serviria de cemitério no jogo de queimada. Refazer a 
questão abriu a possibilidade dos alunos reavaliar a situação e identificar a problemática que envolvia sua decisão, permitindo-lhes a previsão de problemas que talvez implicassem a pratica do jogo nas duas quadras.

A reconsideração expressa a capacidade do individuo de reavaliar a situação e de formular novas soluções para os problemas, dando ocasião ao aprendizado por tentativa e erro, que vai fundamentar o desenvolvimento do indivíduo e muni-lo de maior número de experiências para enfrentar situações futuras. A vivencia desse tipo de interação pode dar a ele condiçōes melhores no caso de vir a se deparar com problema semelhante em outro momento de sua vida (VIGOTSKI, 2003).

\title{
Considerações finais
}

Ao aceitar a mútua constituição entre sujeito e ambiente, a teoria histórico-cultural avança em relação às perspectivas naturalistas e inatistas, já que considera que os seres humanos nascem com potencialidades que, se não forem ativadas, ao longo da história de vida dos indivíduos, jamais se desenvolverão. Nessa teoria, então, para ativar o desenvolvimento é preciso que haja estímulos passíveis de internalização, os quais terão ocorrido durante a interação social (SMOLKA, 2000b).

É nesse contato entre indivíduos, de forma ativa e comprometida, que a interação social ocorre de forma mais efetiva e interessante em ambiente educacional, pois se exige dos alunos atitude de resposta aos problemas e divergências evidenciados entre eles. Tal atitude será resultado de uma nova forma de os alunos enfrentarem suas divergências, fruto de um aprendizado conquistado diante do confrontamento de suas diferenças (FALKENBACH, 2000).

Durante as atividades do projeto foram praticados jogos, que ao serem jogados promoveram situaçōes de interação social, permitindo o compartilhamento de significados individuais atribuídos a cada ação durante a prática da atividade. A interação ajuda a socializar significados - uma vez que permite negociação - no entanto, ela não os padroniza. Considera-se, então, que a interação ajuda a formular acordos sobre significados para possibilitar a comunicação entre indivíduos e a troca de experiências entre eles.

A interação social se constitui, ao nosso ver, num espaço de construção e experimentação. Um lugar para que os sujeitos percebam o meio social e posicionemse sobre as situaçóes, o que possibilita um novo repensar acerca de suas açôes. Daí a importância do presente estudo, pois fica evidenciado que os sujeitos, durante a prática de jogos, vivenciam muito mais que as açôes motoras que são exigidas deles. Eles excluem, incluem, questionam, solicitam, discutem e desafiam, aprendendo a cada novo instante a perceber como o meio social responde às suas ações. Por fim, é preciso lembrar ainda que toda ação humana é idealizada a partir de um emaranhado de experiências dos sujeitos, sendo impossível dissociar suas ações de suas histórias de vida.

\begin{abstract}
Social interaction in physical education classes

This study analyzed forms of social interaction that occur during the practice of children's games. The historicalcultural perspective, especially Vigotski's contributions, was the theoretical framework from which we analyzed social interactions. The experiment, characterized as participative observation, was carried out with children aged nine to 11 years. The proposed mode of conducting the class was of open classes, with efforts to stimulate the children to change the rules of games, through the greatest amount of interaction between them. The data obtained in the work field were categorized into three situational spheres: participation, activity and relationship. The analysis of these spheres suggests that the contact between individuals in an educative environment, in an active and engaged form, produces effective social interactions in the most interesting manner, as it demands attitudes from the students in responding to the problems and divergences that arise between them, many times without adult interference.
\end{abstract}

UnITERMS: Physical education; Social interaction; Internalization. 


\section{Nota}

1. Referenda a João e Maria, música de Sivuca e Chico Buarque de Holanda.

\section{Referências}

DAVIS, C. Piaget ou Vygotsky uma falsa questão. Rio de Janeiro: Ediouro, 2005. p.38-49. (Coleção Memória da Pedagogia, 2).

FALKENBACH, A.P. Desenvolvimento humano e cognição na prática educativa relacional em grupos de crianças com diferentes histórias prévias. Revista Perfil, Porto, v.4, n.4, p.6-14, 2000.

HILDEBRANDT, R.; LAGING, R. Concepções abertas no ensino da educaçáo física. Rio de Janeiro: Ao Livro Técnico, 1986.

LEMOS, T.V. Nas palavras do escritor: um estudo sobre a constituição da subjetividade na infância. Disponível em: <http://www.anped.org.br/25/taisavlieselemost20.rtf>. Acesso em: 5 set. 2006.

PEDROSA, M.I. Investigação da criança em interação social (apresentação). Recife: Ed. Universitária de UFPE, 1996. p.5-10. (Coletânea da ANPEPP, v.1, n.4).

PINO, A.S. O social e o cultural na obra de Vigotski. Educação \& Sociedade, Campinas, v.21, n.71, p.45-78, 2000.

PULETINI, F.A.B. et al. Projeto de educação motora. Campinas: [s.n.]: 2006.

RIBEIRO, S.M. et al. (Org.). Dossiê Prodecad: perspectivas artístico-educacionais (2001-2004).Campinas: [s.n.], 2001. SANTIGOSA, A.S. La interiorización como punto de encuentro entre pensamiento y lenguaje: un debate conceptual. Revista Latina de Pensamiento y Lenguaje, Guadalajara, v.11, n.2, p.143-63, 2003.

SILVA, P.N.G.; BRANDĀO, K.B.; HILDEBRANDT, R. A poética dos gestos dos jogadores. Revista Brasileira de Ciências do Esporte, Campinas, v.27, n.2, p.105-19, 2006.

SMOLKA, A.L.B. Memory at issue: a historical-cultural perspective. Educação \& Sociedade, Campinas, v.21, n.71, 2000a. . The (im)proper and the (im)pertinent in the appropriation of the social practice. Cadernos CEDES, Campinas, v.20, n.50, 2000b.

SMOLKA, A.L.B.; LAPLANE, A.L.F. Processos de cultura e internalização. Rio de Janeiro: Ediouro, 2005. p.76-83. (Coleção Memória da Pedagogia, 2).

TAFFAREL, C.N.Z. Concepção de aulas abertas às experiências em educação física: discussão de pressupostos em relação a fins e objetivos, à luz da realidade da educação física escolar brasileira. Motrivivência, São Cristovão, v.6, n.4, p.41-7, 1993.

UNIVERSIDADE FEDERAL DE PERNAMBUCO/UNIVERSIDADE FEDERAL DE SANTA MARIA. Grupo de Trabalho Pedagógico. Visão didática da educação física: análises críticas e exemplos práticos de aula. Rio de Janeiro: Ao Livro Técnico, 1991. (Coleção Educação Física, Série Fundamentação, 11).

VIGOTSKI, L.S. Psicologia da arte. São Paulo: Martins Fontes, 1999. Manuscrito de 1929. Educação \& Sociedade, Campinas, v.21, n.71, p.21-44, 2000.

. A formação social da mente: o desenvolvimento dos processos psicológicos superiores. 6.ed. São Paulo: Martins Fontes, 2003.

ENDEREÇO

Pedro José Winterstein

R. 12, 424 - Cond. Res. Paineiras - Caixa Postal o3 13140-00o - Paulínia - SP - BRASIL e-mail: winterstein@fef.unicamp.br
Recebido para publicação: 10/06/2008

Revisado: 29/05/2009

Aceito: 20/07/2009 